\title{
Electrophysiological approach to determine kinetic parameters of sucrose uptake by single sieve elements or phloem parenchyma cells in intact Vicia faba plants
}

\author{
Jens B. Hafke ${ }^{1,2 *}$, Sabina-Roxana Höll ${ }^{2}$, Christina Kühn ${ }^{3}$ and Aart J. E. van Bel ${ }^{2}$ \\ 1 Institute of Plant Physiology, Justus-Liebig-University, Giessen, Germany \\ 2 Institute of General Botany, Plant Cell Biology Research Group, Justus-Liebig-University, Giessen, Germany \\ ${ }^{3}$ Department of Plant Physiology, Institute of Biology, Humboldt University, Berlin, Germany
}

\section{Edited by:}

John W. Patrick, The University of

Newcastle, Australia

Reviewed by:

John W. Patrick, The University of

Newcastle, Australia

Nick Gould, Plant and Food

Research, New Zealand

*Correspondence:

Jens B. Hafke, Institute of Plant

Physiology, Justus-Liebig-Universität

Giessen, Senckenbergstrasse 3,

35390, Giessen, Germany

e-mail:jens.hafke@

bot1.bio.uni-giessen.de
Apart from cut aphid stylets in combination with electrophysiology, no attempts have been made thus far to measure in vivo sucrose-uptake properties of sieve elements. We investigated the kinetics of sucrose uptake by single sieve elements and phloem parenchyma cells in Vicia faba plants. To this end, microelectrodes were inserted into free-lying phloem cells in the main vein of the youngest fully-expanded leaf, halfway along the stem, in the transition zone between the autotrophic and heterotrophic part of the stem, and in the root axis. A top-to-bottom membrane potential gradient of sieve elements was observed along the stem $(-130 \mathrm{mV}$ to $-110 \mathrm{mV})$, while the membrane potential of the phloem parenchyma cells was stable (approx. $-100 \mathrm{mV}$ ). In roots, the membrane potential of sieve elements dropped abruptly to $-55 \mathrm{mV}$. Bathing solutions having various sucrose concentrations were administered and sucrose $/ \mathrm{H}^{+}$ induced depolarizations were recorded. Data analysis by non-linear least-square data fittings as well as by linear Eadie-Hofstee $(E H)$-transformations pointed at biphasic Michaelis-Menten kinetics (2 MM, EH: $K_{m 1} 1.2-1.8 \mathrm{mM}, K_{m 2} 6.6-9.0 \mathrm{mM}$ ) of sucrose uptake by sieve elements. However, Akaike's Information Criterion (AIC) favored single MM kinetics. Using single MM as the best-fitting model, $K_{m}$ values for sucrose uptake by sieve elements decreased along the plant axis from 1 to $7 \mathrm{mM}$. For phloem parenchyma cells, higher $K_{m}$ values $\left(E H: K_{m 1} 10 \mathrm{mM}, K_{m 2} 70 \mathrm{mM}\right.$ ) as compared to sieve elements were found. In preliminary patch-clamp experiments with sieve-element protoplasts, small sucrose-coupled proton currents $(-0.1$ to $-0.3 \mathrm{pA} / \mathrm{pF})$ were detected in the whole-cell mode. In conclusion (a) $K_{m}$ values for sucrose uptake measured by electrophysiology are similar to those obtained with heterologous systems, (b) electrophysiology provides a useful tool for in situ determination of $K_{m}$ values, (c) As yet, it remains unclear if one or two uptake systems are involved in sucrose uptake by sieve elements, (d) Affinity for sucrose uptake by sieve elements exceeds by far that by phloem parenchyma cells, (e) Patchclamp studies provide a feasible basis for quantification of sucrose uptake by single cells. The consequences of the findings for whole-plant carbohydrate partitioning are discussed.

\section{INTRODUCTION}

The wide-spread notion that carbohydrate distribution largely results from competition between terminal sinks neglects the role of axial sinks along the pathway and the dynamics of phloem transport (van Bel, 1996, 2003a; Hafke et al., 2005). Studies using ${ }^{11} \mathrm{C}$-labeled substances revealed considerable rates of photoassimilate exchange along the axis of intact Phaseolus plants (Minchin and Thorpe, 1984, 1987). The results indicate a dynamic leakage/retrieval of photoassimilates along the transport phloem (Eschrich et al., 1972; Minchin and Thorpe, 1987; van Bel, 2003b; Gould et al., 2012). Under mostly prevailing source-limiting conditions when sink demand exceeds source supply (Patrick and Offler, 1996), photoassimilates translocated in the sieve-tube sap are steadily leaking into the vascular apoplasmic space. From there, photoassimilates are retrieved by sieve-element/companion-cell complexes (SE/CCs) or absorbed by phloem parenchyma cells (PPCs), which present the borderline of the axial sink area (van Bel, 1996). Competition between SE/CCs and PPCs for photoassimilates was postulated to be a key process regulating photoassimilate partitioning between axial and terminal sinks (van Bel, 1996; Hafke et al., 2005; van Bel and Hafke, 2005). The balance between release and retrieval may also be involved in the maintenance of the hydraulic pressure gradient in transport phloem (Minchin and Thorpe, 1987; van Bel, 1996; Gould et al., 2004; van Bel and Hafke, 2005). 
Under source-limiting conditions, SE/CCs and PPCs seem to represent syplasmically separated domains in transport phloem (van der Schoot and van Bel, 1989; Oparka et al., 1994; van Bel and van Rijen, 1994; Patrick and Offler, 1996; Rhodes et al., 1996; Hafke et al., 2005). Hence, photoassimilate uptake by either SE/CCs or PPCs is dictated by the respective proton motive forces (pmf; e.g., van Bel, 1996). The competitiveness between SE/CCs and PPCs was quantified by pmf measurements in the main vein of intact Vicia faba plants and a few other plant species (Hafke et al., 2005). These studies identified the membrane resting potential as the domineering pmf-component in the competition between SE/CCs or PPCs.

Apart from the pmf, other parameters, in particular $K_{m}$ and $V_{\text {max }}$ of the sucrose transporters determine the competitiveness for photoassimilates between SE/CCs and PPCs. To date, sucroseuptake kinetics of sieve elements has been determined by using entire phloem tissues or sucrose transporters expressed in oocytes and yeast (for reviews see Kühn, 2003; Lalonde et al., 2003; Sauer, 2007; Ayre, 2011; Geiger, 2011). These approaches do not provide conclusive information on the in situ uptake by sieve elements. In the first approach, uptake kinetics of sieve elements are blurred by the contribution of other cell types; in heterologous expression, uptake is taking place in an artificial environment and fails to quantify in situ $V_{\max }$ of sucrose uptake. Furthermore, kinetics of sucrose uptake by PPCs has been largely neglected so that the picture of the competition between SE/CCs and PPCs is far from complete.

The lack of exact information calls for approaches by which the sucrose-uptake kinetics of each single cell type can be measured separately in the natural cell environment. Therefore, we executed depolarization studies (cf. Lichtner and Spanswick, 1981; Wright and Fisher, 1981) using intracellular electrodes. They were impaled into phloem cells to record electrical responses to graded sucrose supply. The magnitude of depolarization allows the calculation of the $K_{m}$ of the transporters involved, but did not provide information on $V_{\text {max }}$. The $V_{\max }$ values depend on the transporter density and the turnover rates. Hence, the feasibility of a wholecell patch-clamp approach was explored to detect and possibly quantify sucrose uptake by sieve-element protoplasts.

\section{METHODS}

\section{PLANT MATERIAL}

Vicia faba cv. Witkiem plants (Nunhems Zaden BV, Haelen, The Netherlands) were grown in pots in a greenhouse at temperatures varying between $20^{\circ} \mathrm{C}$ and $30^{\circ} \mathrm{C}$ at $60-70 \%$ humidity and a 14/10-h light/dark period. Supplementary lamp light (model SONT Agro $400 \mathrm{~W}$; Phillips Eindhoven, The Netherlands) resulted in an irradiance level of $200-250 \mu \mathrm{mol} \mathrm{m}^{-2} \mathrm{~s}^{-1}$ at the plant apex. Test plants were taken 3 weeks after germination (cf. Hafke et al., 2005).

\section{Tissue preparation of intact plants}

Cortical layers of the main vein of the youngest mature leaf or of internodal rims were removed by manual paradermal slicing with a fresh razor blade as described before (Knoblauch and van Bel, 1998). Leaves were mounted on a microscope slide with two-sided adhesive tape and the free-lying tissue was bathed in a weakly buffered standard bathing medium (BM): $2 \mathrm{mM} \mathrm{KCl}, 1 \mathrm{mM} \mathrm{CaCl} 21 \mathrm{mM} \mathrm{MgCl} 2,100 \mathrm{mM}$ mannitol, $2.5 \mathrm{mM}$ 4-morpholinoethanesulfonic acid (MES)/NaOH, pH 5.7. For measurements in internodes being bent into a horizontal plane, a home-made bathing system was used to submerse and perfuse free-lying phloem tissue with various solutes. Intactness of phloem tissue was checked using a microscope (Leica DMLB, fluorescence microscope) equipped with a water immersion objective (HCX APO L40x/0.80 W U-V-I objective, Leica, Heidelberg, Germany) that was insulated from the electrophysiological devices.

\section{Intracellular electrophysiology in intact plants}

Membrane potential measurements in intact phloem tissue have been described in detail (Hafke et al., 2005). Microelectrodes were pulled from aluminosilicate microcapillaries with an outer diameter of $1 \mathrm{~mm}$ and an internal filament (SM100F-10, Harvard Apparatus LTD, Edenbridge, Kent, UK) on a vertical electrode puller (GETRA, München, Germany). The tip diameter of these electrodes was $0.5-1 \mu \mathrm{m}$. The microelectrodes were back-filled with $500 \mathrm{mM} \mathrm{KCl}$ and clamped in an $\mathrm{Ag} / \mathrm{AgCl}$ pellet electrode holder (WPI, Sarasota FL, USA). The microelectrode was connected to the probe of the amplifier (DUO 773 high-input impedance differential electrometer, WPI, Sarasota FL, USA). The Ag/AgCl reference electrode was connected to the bathing medium by a $2 \%$ agar bridge (w/v) filled with $500 \mathrm{mM} \mathrm{KCl}$ solution (Hafke et al., 2005). After incubation in BM for $1 \mathrm{~h}$, microelectrodes were impaled into phloem cells under microscopic surveillance (Hafke et al., 2005). All measurements were performed at a room temperature of $23-25^{\circ} \mathrm{C}$. Membrane potentials of sieve elements (SEs) and adjacent phloem parenchyma cells (PPCs) were recorded either in main veins or in internodes along the plant. The term plant length index (PLI) was introduced to define the recording positions. The main vein of youngest mature leaf was defined as PLI 1, a position half-way along the stem as PLI 0.5, and the position at the transition between the autotrophic and heterotrophic part of the stem as PLI 0 (Figure 1A).

\section{Measurement of sucrose-induced depolarizations in intact phloem tissue}

Various sucrose concentrations $(1-100 \mathrm{mM})$, dissolved in BM, were administered to the bare-lying phloem tissue. Because the membrane potential measurements - in particular those of PPCs - are extremely sensitive to perfusion turbulence, sucrose solutions were supplied via a microcapillary $(20-30 \mu \mathrm{m}$ in diameter) mounted on a micromanipulator and connected to a pressure-driven microinjector (Cell Tram Oil microinjector, Eppendorf, Hamburg, Germany).

Sucrose-induced depolarizations (e.g., Lichtner and Spanswick, 1981) were plotted against the sucrose concentration. $K_{m}$-values for sucrose uptake by SE/CCs or PPCs for the uptake models MM (single Michaelis-Menten term) and $2 \mathrm{MM}$ (two Michelis-Menten terms) were obtained by non-linear least square fitting (NLSF) using SIGMA PLOT 11.2 software package (Systat Software, San Jose, CA). Goodness-of-fit was judged from $R^{2}$ and the sum of squared residuals (SSR). A smaller SSR is 

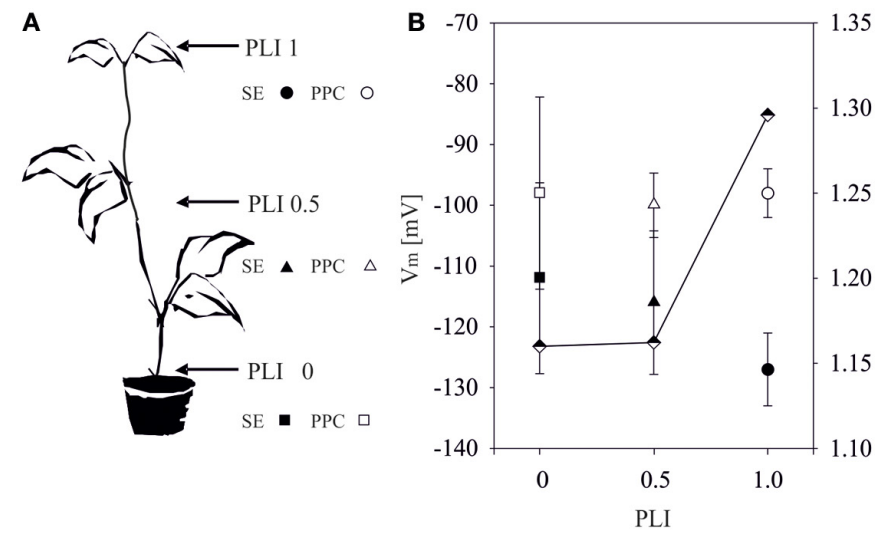

D

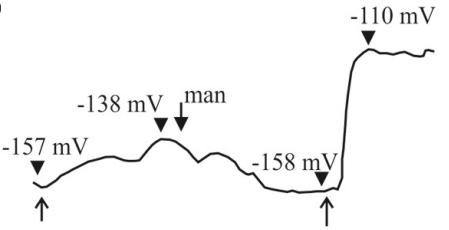

10 suc pH 5.7 10 suc pH $3.5-109 \mathrm{mV}$

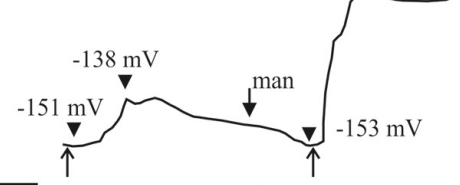

$\overline{2 \min } 10$ suc $\mathrm{pH} 5.7 \quad 10$ suc $\mathrm{pH} 3.5$

G
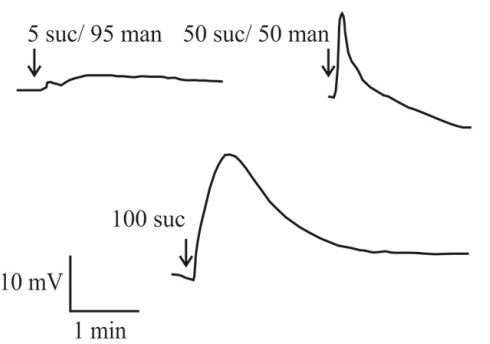
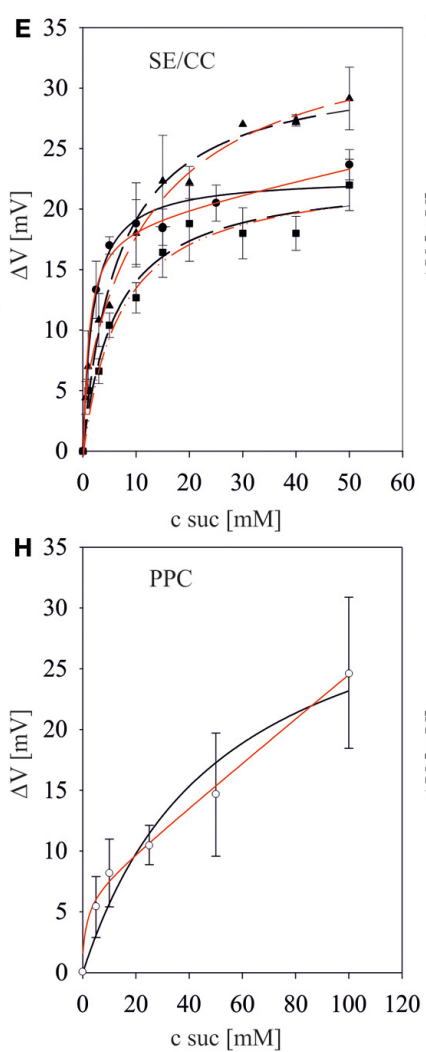

C
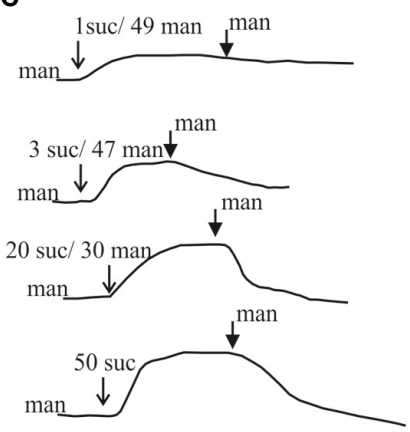

$10 \mathrm{mV} \frac{}{2 \mathrm{~min}}$
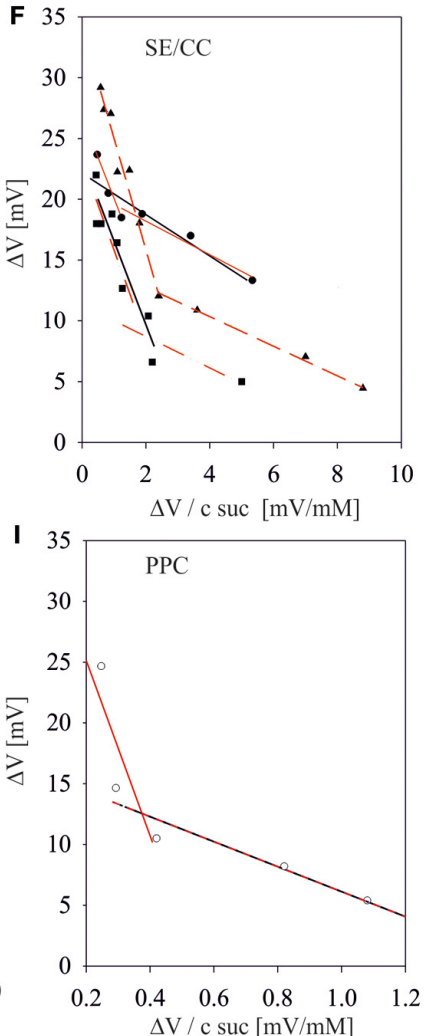

FIGURE 1 | Sucrose-induced depolarizations in sieve-elements (SEs) and phloem parenchyma cells (PPCs) along the stem of intact Vicia faba plants. (A) Plant length indices (PLIs: 1.0, mid-vein of the youngest mature leaf; 0.5, half-way the stem; 0, stem-to-root transition area) standardize the microelectrode positions along plants of diverse lengths. The symbols (circles, triangles, squares) associated with certain PLIs are used in the following figures. The numbers associated with sucrose (suc) and mannitol (man) in the following figures represent their concentrations (mM). (B) Membrane potential resting levels ( $V_{m}, \pm S D$, left $y$-axis) in SE/CCs and PPCs along the plant axis. Membrane potential ratios $\left(V_{\mathrm{mSE} / \mathrm{CC}} / V_{\mathrm{mPPC}}\right.$, semi-filled diamonds, right $y$-axis) along the phloem pathway. (C) Typical recorder traces showing the time-course of the change in SE membrane potentials at PLI 1.0 in response to the addition of 1, 3, 20 and $50 \mathrm{mM}$ sucrose, respectively. The start of perfusion with test solutions is marked by arrows, that of mannitol rinsing by fat arrows. (D) $\mathrm{pH}$-dependence of sucrose uptake into single SEs. Depolarizations in response to $10 \mathrm{mM}$ sucrose $\mathrm{pH} 5.7$ and $10 \mathrm{mM}$ sucrose $\mathrm{pH} 3.5$ intermitted by rinsing with mannitol. The start of perfusion with test solutions is marked by arrows, that of mannitol rinsing by fat arrows. Arrowheads mark the membrane voltage. (E) Relationship between sucrose-induced depolarizations ( $y$-axis) of SEs and external sucrose concentrations at $\mathrm{pH}$ 5.7 ( $x$-axis) at different PLIs ( $n=5$ to 10 for each concentration). Data points where fitted either to a single MM term (black line) or to the biphasic MM equation (red line) (F) Eadie-Hofstee transformation of sucrose-induced depolarization as a measure for sucrose uptake at different PLIs for SEs. In Eadie-Hofstee plots, the negative slopes of linear fits represent the $-K_{m}$ values. For linear regressions of the data from PLI 1 and PLI 0 either a single MM (black line) or a biphasic MM (red line) kinetic is assumed. For PLI 0.5 two components were unequivocally identified (G) Typical recorder traces showing the time-course of the change in PPC membrane potential at PLI 1.0 in response to 5,50 and $100 \mathrm{mM}$ sucrose, respectively. (H) Relationship between membrane potential depolarizations $(\Delta \mathrm{V}, y$-axis) and supplied sucrose concentrations ( $x$-axis) of PPCs at PLI 1 at $\mathrm{pH} 5.7$ ( $n=10$ for each concentration). Data points where fitted either to a single MM term (black line) or biphasic MM term (red line). (I) Eadie-Hofstee transformation of sucrose-induced depolarization of PPCs at PLI 1. 
indicative of a tight fit of the model to the data (e.g., Ritchie and Prvan, 1996; Motulsky and Christopoulos, 2003). The formulas applied are exemplified by the following biphasic MM equation for two active transport systems (2 MM terms) (1):

$$
\Delta V=\frac{\Delta V_{1}[\mathrm{suc}]_{\mathrm{ext}}}{K_{m 1}+[\mathrm{suc}]_{\mathrm{ext}}}+\frac{\Delta V_{2}[\mathrm{suc}]_{\mathrm{ext}}}{K_{m 2}+[\mathrm{suc}]_{\mathrm{ext}}}
$$

in which $\Delta \mathrm{V}=$ amplitude of depolarization, $\Delta \mathrm{V}_{1}, \Delta \mathrm{V}_{2}$ the maximum depolarization in analogy to $V_{\max }$ and $K_{m}$ describes the $\mathrm{MM}$ constant of the transport system. Here, $K_{m}$ is the concentration at which $50 \%$ of the maximal depolarization is reached. $K_{m}$ values were also calculated from Eadie-Hofstee (EH) transformations (Hofstee, 1959) assuming either a single MM (one slope; $-K_{m}$ ) or a biphasic $2 \mathrm{MM}$ kinetic (two different slopes, $\left.-K_{m 1},-K_{m 2}\right)$. The $\mathrm{EH}$ transformation for one slope is given by (2):

$$
\Delta V=\Delta V_{\max }-K_{m} \frac{\Delta V}{[\mathrm{suc}]_{\mathrm{ext}}}
$$

\section{Model selection using Akaike's Information Criterion (AIC)}

Akaike's (entropy-based) Information Criterion (Akaike, 1973, cited in Burnham and Anderson, 2004) is an approach to select the best model from a set of models. The AIC determines how well the data supports each model (for details please see Motulsky and Christopoulos, 2003; Burnham and Anderson, 2004). It has an in-built penalty for models which larger number of parameters (more complex models). The model which fits well but has a minimum number of parameters (simplicity and parsimony) is preferred (Burnham and Anderson, 2004). In the present work AIC-based model selection was used to discriminate between single MM or double MM (2 MM) sucrose-uptake kinetics.

For a quantitative comparison of different models, an AIC value is determined for each model. For small sample sizes, Akaike's second-order information criterion $\left(\mathrm{AIC}_{\mathrm{c}}\right.$; e.g., Motulsky and Christopoulos, 2003; Burnham and Anderson, 2004) is used for calculation which is given by Equation (3):

$$
\mathrm{AIC}_{\mathrm{c}}=N \operatorname{In} \frac{\mathrm{SSR}}{N}+2 K+\frac{2 K(K+1)}{N-K-1}
$$

where $\mathrm{N}$ is the number of data points, SSR is the sum of squared residuals obtained from non-linear least-square fittings (either to the model $\mathrm{MM}$ or $2 \mathrm{MM}$ ) to the data points and $\mathrm{K}$ is the number of parameters to be fitted plus one (Motulsky and Christopoulos, 2003). The number of parameters is 2 for MM and 4 in case of $2 \mathrm{MM}$. The model with the lower AIC value is more likely to be correct. If AICc values are very close or equal, there is no evidence to prefer one model over the other or each model is equally likely to be correct (Motulsky and Christopoulos, 2003). For a more quantitative comparison of models, the strength of evidence for each model is determined by calculating $\Delta_{i}(=$ delta AIC) and Akaike's weight $w_{i}$, respectively. $\Delta_{i}$ is simply calculated by subtraction of the $\mathrm{AIC}_{\mathrm{c}}$ value for the best model (= minimum $\mathrm{AIC}_{\mathrm{c}}$ value) from the $\mathrm{AIC}_{\mathrm{c}}$ value of the other model(s) (e.g., Burnham and Anderson, 2004). $\Delta_{i}$ are then transformed into Akaike's weight (4):

$$
w_{i}=\frac{e^{-0.5 \Delta i}}{1+e^{-0.5 \Delta i}}
$$

Akaike weights $\left(w_{i}\right)$ are the "weight of evidence" in favor of a certain model being the best model in the candidate set (e.g., Burnham and Anderson, 2004). From Akaike's weight, an evidence ratio of probabilities can be calculated by (5):

Evidence ratio $=\frac{\text { Probabilty that model } 1 \text { is correct }}{\text { Probabilty that model } 2 \text { is correct }}=\frac{1}{1+e^{-0.5 \Delta_{i}}}$

The evidence ratio indicates how many times more likely is one model compared to the other (Motulsky and Christopoulos, 2003).

\section{Isolation of sieve-element protoplasts and patch-clamp recordings}

Sieve-element protoplasts were isolated according to Hafke et al. (2007). Internodes from 3 to 4 weeks old plant were excised and split longitudinally. For coarse mechanical isolation of phloem strands, vascular tissues were sliced (slice thickness $\sim 300 \mu \mathrm{m}$ ) with a razor blade from the cut tangential face of the internode. The slices were transferred into an enzymatic wall digestion medium (Hafke et al., 2007) and incubated over night (approx. $10 \mathrm{~h}$ ) at room temperature. Disintegrating phloem strands were filtered through an $80 \mu \mathrm{m}$ nylon mesh, washed two times and stored in a medium containing $500 \mathrm{mM}$ mannitol, $2 \mathrm{mM} \mathrm{KCl}$, $1 \mathrm{mM} \mathrm{CaCl} 2,1 \mathrm{mM} \mathrm{MgCl} 2,2.5 \mathrm{mM} \mathrm{MES/NaOH}, \mathrm{pH}$ 5.7. Only simple sieve-element protoplasts that were identified by inclusion of forisomes, were used for patch clamp experiments (cf. Hafke et al., 2007)

A cytosolic solution (pipette solution in contact with the cytoplasmic side of the protoplast) was slightly modified in comparison to Carpaneto et al. (2005) and contained $30 \mathrm{mM} \mathrm{KCl}, 1 \mathrm{mM}$ EGTA, $3 \mathrm{mM} \mathrm{MgCl}_{2}$, $5 \mathrm{mM}$ sucrose, $400 \mathrm{mM}$ mannitol, $10 \mathrm{mM}$ BTP (bis-tris-propane), titrated with MES to $\mathrm{pH}$ 7.5. Protoplasts were bathed in a solution composed of $2 \mathrm{mM} \mathrm{MgCl}_{2}, 1 \mathrm{mM}$ $\mathrm{CaCl}_{2}, 1 \mathrm{mM} \mathrm{GdCl}$, $450 \mathrm{mM}$ mannitol, $10 \mathrm{mM} \mathrm{MES}$, titrated with BTP to $\mathrm{pH}$ 5.5. For sucrose application, $450 \mathrm{mM}$ mannitol was replaced by $350 \mathrm{mM}$ mannitol and $100 \mathrm{mM}$ sucrose as compared to the bathing solution. This solution was delivered in the vicinity of the protoplast via a microcapillary connected to a pressure-driven microinjector.

Patch-clamp recordings on sieve-element protoplasts were performed in the whole-cell configuration as described before (cf. Hafke et al., 2007). Whole-cell currents were recorded with an A-M Systems patch-clamp amplifier (Model 2400, A-M Systems, Inc. ${ }^{\circledR}$, Carlsborg, USA), filtered with an eight-pole Bessel filter at either 0.5 or $1 \mathrm{kHz}$ and stored online on a personal computer at a $2,5 / 5 \mathrm{kHz}$ sampling frequency via a Digidata 1440A interface digitizer (Molecular Devices, MDS Analytical Technologies, Sunnydale, California, USA). Data were low-pass filtered off-line at 10 or $25 \mathrm{~Hz}$. Data recording, acquisition and analysis were performed with pCLAMP 10 hardware and software facilities (Molecular Devices Corporation, Sunnydale, California, USA). For comparison of individual protoplasts, current amplitudes were normalized to the whole-cell membrane 
capacitance. Membrane capacitance was determined from capacitive currents measured in response to short $(10 \mathrm{~ms})$ voltage steps of $10 \mathrm{mV}$ (Gillis, 1995). All command voltages were corrected off-line for liquid junction potential (Neher, 1992) using a Liquid Junction Potential Calculator (Ng and Barry, 1995). All measurements were carried out at room temperatures of about $21^{\circ} \mathrm{C}$.

\section{RESULTS \\ MEMBRANE POTENTIALS OF SIEVE ELEMENT/COMPANION CELL COMPLEX (SE/CCS) AND PHLOEM PARENCHYMA CELLS (PPCS) ALONG THE PLANT AXIS}

Under the usually prevailing source-limiting conditions, the dynamic sucrose exchange along the transport phloem is controlled by pmf-driven transporters located at the plasmamembranes of SE/CCs and PPCs. Earlier studies pointed out that competitiveness between SEs and PPCs is determined by the electric component of the pmf (Hafke et al., 2005). Hence, membrane potentials of SE/CCs and PPCs were determined along the axis of intact Vicia faba plants after impalement by microelectrodes under microscopic surveillance as illustrated previously (Hafke et al., 2005).

To standardize the electrode positions along plants of various lengths, the plant length index (PLI) was introduced (Figure 1A). The position on the main vein of the youngest mature leaf was set to be PLI 1, a position halfway along the stem was defined as PLI 0.5 and the transition from the heterotrophic to the autotrophic region just above ground level corresponds to PLI 0 . The resting potentials of SE/CCs and PPCs were recorded at the respective plant axis positions and the membrane potential ratios $V_{\mathrm{m} \mathrm{SE} / \mathrm{CC}} / V_{\mathrm{m} \text { PPC }}$ calculated (Figure 1B).

The average membrane potentials of SE/CCs (Figure 1B) varied between $-127 \mathrm{mV}$ at PLI 1 and $-112 \mathrm{mV}$ at PLI 0 and those of the PPCs remain around $-100 \mathrm{mV}$ along the entire stem stretch. The distinct and consistent difference between the membrane potentials of SE/CCs and PPCs at various PPIs indicated a symplasmic disjunction as found before in transport phloem (Oparka et al., 1994; van Bel and van Rijen, 1994; Kempers et al., 1998; Hafke et al., 2005). Since the membrane potentials of the SE/CCs declined more rapidly along the plant axis than those of the PPCs (see ratio, Figure 1B), the relative competitiveness of the PPCs may increase towards the stem base.

Membrane potentials were also recorded in SEs and PPCs embedded in free-lying vascular root tissue. There, the SE membrane potentials are drastically reduced to $-55 \pm 2.4 \mathrm{mV}(n=4)$ in comparison with SEs in the stem. No stable values for PPCs could be obtained so that no conclusions could be drawn regarding the relative competitiveness between SEs and PPCs in roots.

\section{$K_{m}$ VALUES OF SUCROSE UPTAKE IN EITHER SE/CCS OR PPCS MEASURED BY SUCROSE-INDUCED DEPOLARIZATION OF MEMBRANE POTENTIALS}

As discussed before (Hafke et al., 2005), kinetics of sucrose uptake by SE/CCs and PPCs is a key element in the competitiveness between SE/CCs and PPCs and, hence, for photoassimilate partitioning. However, the cell-specific uptake kinetics has not been determined conclusively to date. Studies of ${ }^{14} \mathrm{C}$-sucrose uptake by phloem strips do not discriminate between the kinetics of SE/CCs and PPCs. Furthermore, uptake studies using SE- and PPC-protoplasts would require an immense amount of protoplasts which is virtually impossible given the painstaking isolation and identification procedures. Therefore, we measured membrane depolarizations of single cells induced by various apoplasmic sucrose concentrations under physiological conditions (e.g., Lichtner and Spanswick, 1981). Natural apoplasmic sucrose concentrations are in the range between 1.0 and $60.0 \mathrm{mM}$ (cf. Patrick and Turvey, 1981; Minchin and Thorpe, 1984; Voitsekhovskaja et al., 2000; Kang et al., 2007).

As reported before (Hafke et al., 2005), microelectrodes were impaled into SEs (Figures 1C,D) or PPCs (Figure 1G). Following stabilization of the membrane potential, various sucrose concentrations were supplied to SE/CCs by bath perfusion (for SEs) or local micropipette-mediated solute administration (for PPCs). Electrical recordings showed graded effects of various sucrose concentrations on the membrane potentials of SEs (Figure 1C) and PPCs (Figure 1G). As a general pattern, a fast sucroseinduced depolarization brought about by $\mathrm{H}^{+}$co-transport (e.g., Carpaneto et al., 2005) was followed by a gradual repolarization. Replacement of the sucrose solutions by an iso-osmotic mannitol solution accelerated the repolarization to the resting potential (Figure 1C).

At a decreased external $\mathrm{pH}$ (3.5 instead of 5.7), application of the same sucrose concentration $(10 \mathrm{mM})$ resulted in a 3 -fold increase in the magnitude of depolarization (Figure 1D) which is in agreement with the role of protons in pmf-driven $\mathrm{H}^{+}$sucrose symport (e.g., Delrot and Bonnemain, 1981; Reinhold and Kaplan, 1984).

The relationship between sucrose concentration and SE or PPC depolarization can be described by single Michaelis-Menten kinetics (MM) or a biphasic Michaelis-Menten kinetics (2 MM) (Figures 1E,H). Regression diagnostics (sum of squared residuals SSRs, $R^{2}$ ) from non-linear least-square data fitting (NLSF) revealed a slightly better fit to $2 \mathrm{MM}$ as indicated by smaller SSRs and a higher $R^{2}$ as compared to MM (Table 1). Furthermore Eadie-Hofstee (EH) transformations revealed two linear components (Figures 1F,I) which are indicative for two separate, simultaneously operating uptake systems (e.g., Reinhold and Kaplan, 1984). The $K_{m}$ values of either uptake system can be calculated from the linear regression at low and high sucrose concentrations.Unmistakable biphasic uptake kinetics are visible for the SE data at PLI 0.5 (Figure 1F, Table 1), but those at PLI 1 and PLI 0, data can be interpreted to be due to either MM or $2 \mathrm{MM}$ (Figure 1F, Table 1).

Diagnostic tools like SSR and $R^{2}$ values alone do not allow predictions on the adequacy of a kinetic model (MM or $2 \mathrm{MM}$ ). Akaikes Information Criterion (AIC, Motulsky and Christopoulos, 2003; Burnham and Anderson, 2004) was applied to test for the best model (Table 2). MM is more likely to be correct then $2 \mathrm{MM}$ which is indicated by smaller $\mathrm{AIC}_{\mathrm{c}}$ values for the MM model (Table 2). The small difference in $\Delta_{I}$ of $<2$ at PLI 0.5 (1.82) indicates that $2 \mathrm{MM}$ has a substantial support (evidence) whereas models having $\Delta_{I}>10$ (in case of 2 MM at PLI1 and PLI0) have essentially no support (Burnham and Anderson, 
Table 1 | Summary of $K_{m}$-values for sucrose uptake into SE/CCs or PPC obtained by non-linear least-square fitting (NLSF) using SIGMA PLOT 11.2 or Eadie-Hofstee transformation.

\begin{tabular}{|c|c|c|c|c|c|c|c|c|c|c|c|}
\hline \multirow{2}{*}{$\begin{array}{l}\text { Model ID } \\
\text { PLI } \\
\text { Cell type }\end{array}$} & \multicolumn{2}{|c|}{$\begin{array}{c}\text { NLSF } \\
\text { MM }\end{array}$} & \multicolumn{2}{|c|}{$\begin{array}{c}\text { Eadie-Hofstee } \\
\text { MM }\end{array}$} & \multicolumn{3}{|c|}{$\begin{array}{l}\text { NLSF } \\
2 \mathrm{MM}\end{array}$} & \multicolumn{4}{|c|}{$\begin{array}{c}\text { Eadie-Hofstee } \\
2 \mathrm{MM}\end{array}$} \\
\hline & $\begin{array}{l}K m_{1} \\
\pm S E\end{array}$ & $\begin{array}{l}R^{2} \\
\text { SSR }\end{array}$ & $K m_{1}$ & $R^{2}$ & $\begin{array}{l}K m_{1} \\
\pm S E\end{array}$ & $\begin{array}{l}K m_{2} \\
\pm S E\end{array}$ & $\begin{array}{l}R^{2} \\
\mathrm{SSR}\end{array}$ & $K m_{1}$ & $R^{2}$ & $K m_{2}$ & $R^{2}$ \\
\hline 1 & 1.86 & 0.98 & 1.7 & 0.86 & 1.0 & $2.92 \times 10^{8}$ & 0.99 & 1.4 & 0.92 & 6.6 & 0.93 \\
\hline PPC & \pm 26.5 & 21.67 & & & \pm 2.21 & $\pm 2 \times 10^{15}$ & 1.32 & & & & \\
\hline 0.5 & 6.76 & 0.98 & N.d. ${ }^{a}$ & N.d & 0.23 & 14 & 0.99 & 1.2 & 0.99 & 9.0 & 0.96 \\
\hline SE/CC & \pm 1.18 & 22.57 & & & \pm 0.44 & \pm 4.9 & 5.86 & & & & \\
\hline 0 & 6.32 & 0.97 & 6.9 & 0.88 & $1.78 \times 10^{-9}$ & 9.47 & 0.97 & 1.8 & 0.77 & 7.0 & 0.64 \\
\hline SE/CC & \pm 1.33 & 14.86 & & & \pm 2.37 & \pm 8.24 & 12.1 & & & & \\
\hline
\end{tabular}

Sucrose-uptake parameters of the concentration-dependence of the sucrose-induced depolarizations were fitted to a Michaelis-Menten equation (MM) and the sum of two MMs (2 MM). $K_{m}$ values were also obtained from the linear fittings of Eadie-Hofstee transformations (MM, 2 MM). Goodness-of-fit was evaluated from R2 and SSR. A small SSR is indicative of a tight fit of the model to the data. Standard errors (SE) of the fitted parameters are given for the non-linear fittings.

${ }^{a}$ N.d.: not determined. Given the distinct biphasic character of the EH transformation, a linear regression of the data points with only one $K_{m}$ value is not appropriate.

Table 2 | Comparing and selecting different models (MM, 2 MM) by Akaike's second-order information criterion.

\begin{tabular}{lllllll}
\hline PLI & Model ID & AIC $_{\mathbf{c}}$ & $\boldsymbol{\Delta}_{\boldsymbol{i}}$ & $\boldsymbol{w}_{\boldsymbol{i}}(\%)$ & $\begin{array}{l}\text { Evidence } \\
\text { ratio }\end{array}$ & $\begin{array}{l}\text { Best } \\
\text { model }\end{array}$ \\
\hline $\mathbf{1}$ SE & MM & 13.86 & 0 & $1(100)$ & - & MM \\
& $2 \mathrm{MM}$ & 59.97 & 46.11 & 0 & & \\
$\mathbf{0 . 5} \mathbf{S E}$ & $\mathrm{MM}$ & 13.26 & 0 & $0.713(71.3)$ & 2.48 & $\mathbf{M M} /$ \\
& $2 \mathrm{MM}$ & 15.07 & 1.82 & $0.287(28.1)$ & & $2 \mathrm{MM}$ \\
$\mathbf{0} \mathbf{5}$ SE & $\mathrm{MM}$ & 13.96 & 0 & $0.999(99.1)$ & - & $\mathbf{M M}$ \\
& $2 \mathrm{MM}$ & 26.91 & 12.95 & $0.001(0.01)$ & & \\
\hline
\end{tabular}

Denotations: AICC: AIC value, $\Delta_{i}$ : delta $A / C_{C} W_{i}$ : Akaike's weight. For the definitions of the AIC parameters please see Methods section.

2004). Fitting the data to MM would render a shift in $K_{m}$ values for SEs along the plant axis (Table 1). $K_{m}$ values obtained by NLSF increased from $1.86 \mathrm{mM}$ (EH: $1.73 \mathrm{mM}$ ) at PLI1 to $6.32 \mathrm{mM}(\mathrm{EH}$ : $9 \mathrm{mM}$ ) at PLI 0 (Table 1) suggesting a decreased sucrose retrieval by SEs along the plant axis.

For PPCs, a $K_{m}$ value of $52 \pm 26.5 \mathrm{mM}$ showing a high standard error was calculated (Table 1) when MM was adopted as the mode of uptake. Using $2 \mathrm{MM}$, Eadie-Hofstee calculations produced $K_{m 1}$ and $K_{m 2}$ values of 10 and $70 \mathrm{mM}$, respectively, while NLSF revealed a $K_{m 1}$ value of $1.45 \mathrm{mM}$ and infinitesimal high $K_{m 2}$ (Table 1). Irrespective of the mode(s) of uptake, it suggests that the affinity for sucrose uptake is much lower in PPCs than in SEs.

\section{MEASURABILITY OF SUCROSE/H+ TRANSPORTER ACTIVITY IN THE PLASMA MEMBRANE OF SIEVE-ELEMENT PROTOPLASTS}

In analogy to studies of the phloem-localized sucrose carrier ZmSUT1 expressed in Xenopus oocytes (Carpaneto et al., 2005), patch-clamp technique was applied to SE protoplasts in the whole-cell configuration (cf. Hafke et al., 2007) for a direct detection of the sucrose/ $\mathrm{H}^{+}$transporter activity. SE protoplasts (Figure 2A) were bathed in a sucrose-free medium ( $\mathrm{pH}$ 5.5; Figure 2B) and clamped to a holding voltage of $-106 \mathrm{mV}$. In response to external supply of $100 \mathrm{mM}$ sucrose ( $\mathrm{pH} 5.5$ ) by local bath perfusion, an increase in inward current (positive current into the cell, cf. Bertl et al., 1992) was recorded. Normalized currents were in the range of -0.1 to $-0.3 \mathrm{pA} / \mathrm{pF}$ $(-0.2 \pm 0.07 \mathrm{pA} / \mathrm{pF}, n=4)$. This time-dependent increase in negative currents (downward deflections, Figures 2C-E) represent proton currents generated by a $\mathrm{H}^{+}$/sucrose symporter mediating sucrose transport into SEs as reported for ZmSUT1 expressed in Xenopus oocytes (Carpaneto et al., 2005).

\section{DISCUSSION}

\section{In situ DETERMINATION OF $\kappa_{m}$ VALUES FOR SUCROSE UPTAKE BY PHLOEM CELLS USING ELECTROPHYSIOLOGY}

Kinetic parameters for sucrose uptake are crucial for the competition between SE/CCs and PPCs in transport phloem and the distribution of photoassimilates over axial and terminal sinks (van Bel, 1996; Hafke et al., 2005). Other than in previous approaches, $K_{m}$ values for sucrose uptake were calculated here by measuring sucrose-induced membrane depolarizations of SEs and PPCs (Figure 1) in analogy to an approach using cut aphid stylets in combination with electrophysiology (Wright and Fisher, 1981). As aphid stylets are solely inserted into SEs, the latter technique is not applicable for PPC recordings.

The sucrose-induced depolarizations are consistent with $\mathrm{H}^{+}$. sucrose co-transport with a 1:1 stoichiometry (e.g., Lichtner and Spanswick, 1981; Wright and Fisher, 1981; Carpaneto et al., 2005). The magnitude of depolarization varies with external sucrose concentrations in keeping with Michaelis-Menten uptake kinetics (Figures 1E,H). The $K_{m}$ values calculated for uptake by sieve elements (Table 1) match well with those obtained by uptake studies in oocytes and yeast (Figure 3) which can be 

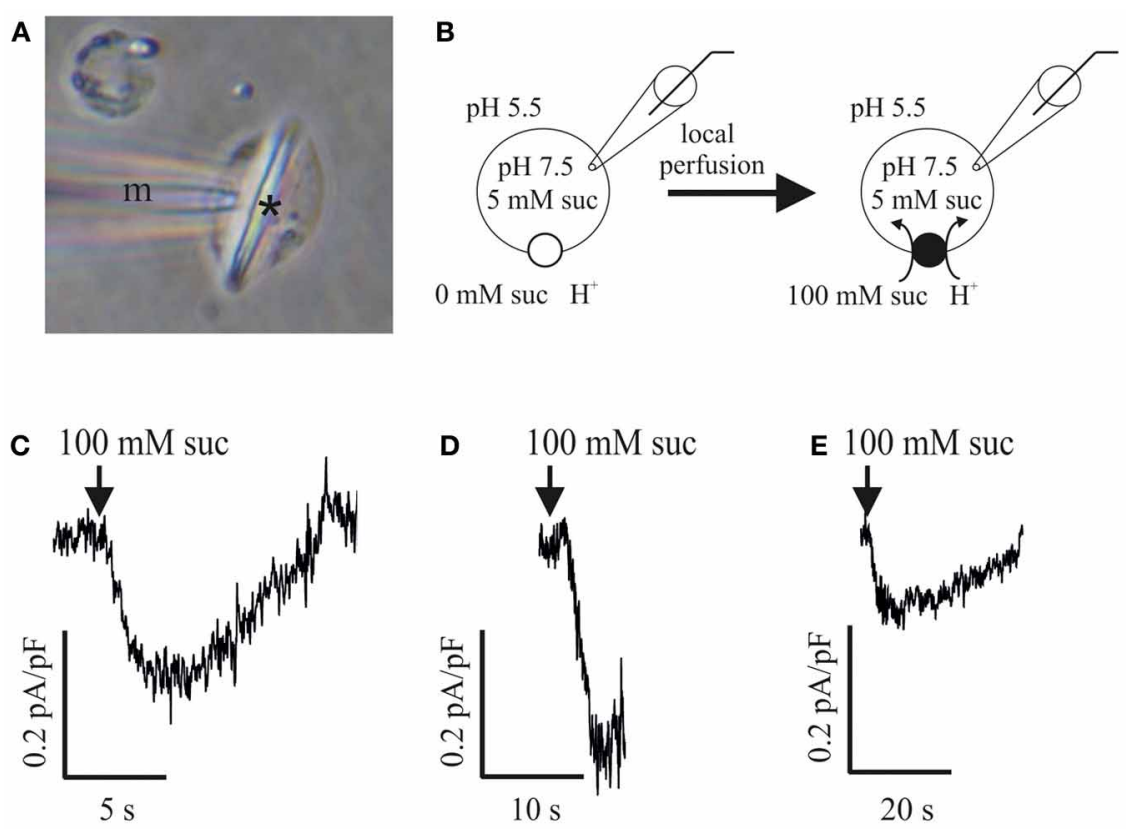

FIGURE 2 | Patch clamp recordings of sucrose-induced $\mathrm{H}^{+}$currents in sieve-element (SE) protoplasts of Vicia faba. (A) SE protoplast containing a forisome (asterisk) with microcapillary $(\mathrm{m})$ attached to the plasma membrane immediately before a patch-clamp experiment. (B) Experimental patch-clamp conditions with $5 \mathrm{mM}$ sucrose at the inner side of an SE protoplast (pipette $\mathrm{pH}$ 7.5) and $0 \mathrm{mM}$ sucrose at the beginning of the experiment (left) and
$100 \mathrm{mM}$ sucrose during perfusion (right) at the outer side (bath $\mathrm{pH}$ 5.5). (C-E) Three independent measurements of sucrose-induced $\mathrm{H}^{+}$-currents in SE protoplasts. Membrane voltage was clamped to $-106 \mathrm{mV}$. Current traces showing a downward deflection (increase in inwardly directed currents) in response to $100 \mathrm{mM}$ sucrose application (arrows). All currents were normalized to the membrane capacitance $\mathrm{C}_{\mathrm{m}}$. regarded as proof for the adequacy of the present electrophysiological approach. The $K_{m}$ values (Table 1) are higher than those observed for sucrose uptake by isolated Commelina minor veins $(0.5 \mathrm{mM})$, but determination of the parameters of active uptake may have been confounded by an appreciable diffusional uptake component in this study (van Bel and Koops, 1985).

\section{SELECTION OF THE KINETIC MODEL}

Plotting the relationship between sucrose concentration and membrane depolarization can be described by either single (MM) or biphasic Michaelis-Menten kinetics (2 MM). As for SEs, EadieHofstee transformations revealed some evidence in favor of two uptake systems (Figure 1F, Table 1), but the differences in significance between $\mathrm{MM}$ or $2 \mathrm{MM}$ were marginal. To distinguish between MM and $2 \mathrm{MM}$, Akaike's Information Criterion (AIC)based model selection was invoked for further analysis (Table 2). As a result, MM is favored for SEs at PLI 1 and PLI 0 (Table 2), whereas AIC supported also $2 \mathrm{MM}$ for SEs at PLI 0.5 (see also Figure 1F) by a difference in $\mathrm{AIC}_{\mathrm{C}}$ values between $\mathrm{MM}$ and $2 \mathrm{MM}$ of $\Delta_{i}<2$ (e.g., Burnham and Anderson, 2004).

The inconclusive assessment of the uptake mode(s) which may also be due to the limited data sets, leaves us with two possible interpretations:

(a) Only one single active uptake system is involved, but MM kinetics is distorted by artifacts induced by the experimental approach. Uptake may be influenced by unstirred layers in vicinity of the plasma membrane as described for intestinal studies (Thomson, 1977; Thomson and Dietschy, 1977; Gardner and Atkinson, 1982). The absorption of solutes in anatomical complex tissues leads to concentrations in the close vicinity of the cell membrane being lower than that in the bulk fluid leading to a deformation of the MichaelisMenten kinetic or the Eadie-Hofstee transformation and a serious shift in $K_{m}$ of the sucrose uptake system to higher values (Winne, 1977; Thomson, 1977; Thomson and Dietschy, 1977; Gardner and Atkinson, 1982). Diffusion through the cell-wall microfibrils may be limited by physical forces in the cell-wall micro-environment.

A further pitfall causing dual kinetics may be symplasmic coupling in intact tissues: biphasic kinetics could be ascribed to differential contributions of electrically coupled cells. Therefore, symplasmic isolation is an absolute prerequisite for a correct interpretation of the data. Fluorochrome studies demonstrated that SE/CCs in transport phloem are strictly disjunct from PPCs under the present conditions (van Bel and van Rijen, 1994; Patrick and Offler, 1996; Knoblauch and van Bel, 1998; Hafke et al., 2005), when the few plasmodesmata in the SE/CC-PPC interface (Kempers et al., 1998) are closed. By contrast, SEs and CCs are strongly coupled in situ via numerous PPUs (Kempers et al., 1998). However, electrode impalement likely confers occlusion by PPUs (Knoblauch and van Bel, 1998) so that the biphasic depolarization patterns are to be merely ascribed to SEs. For PPCs, it remains uncertain to which degree plasmodesmata 


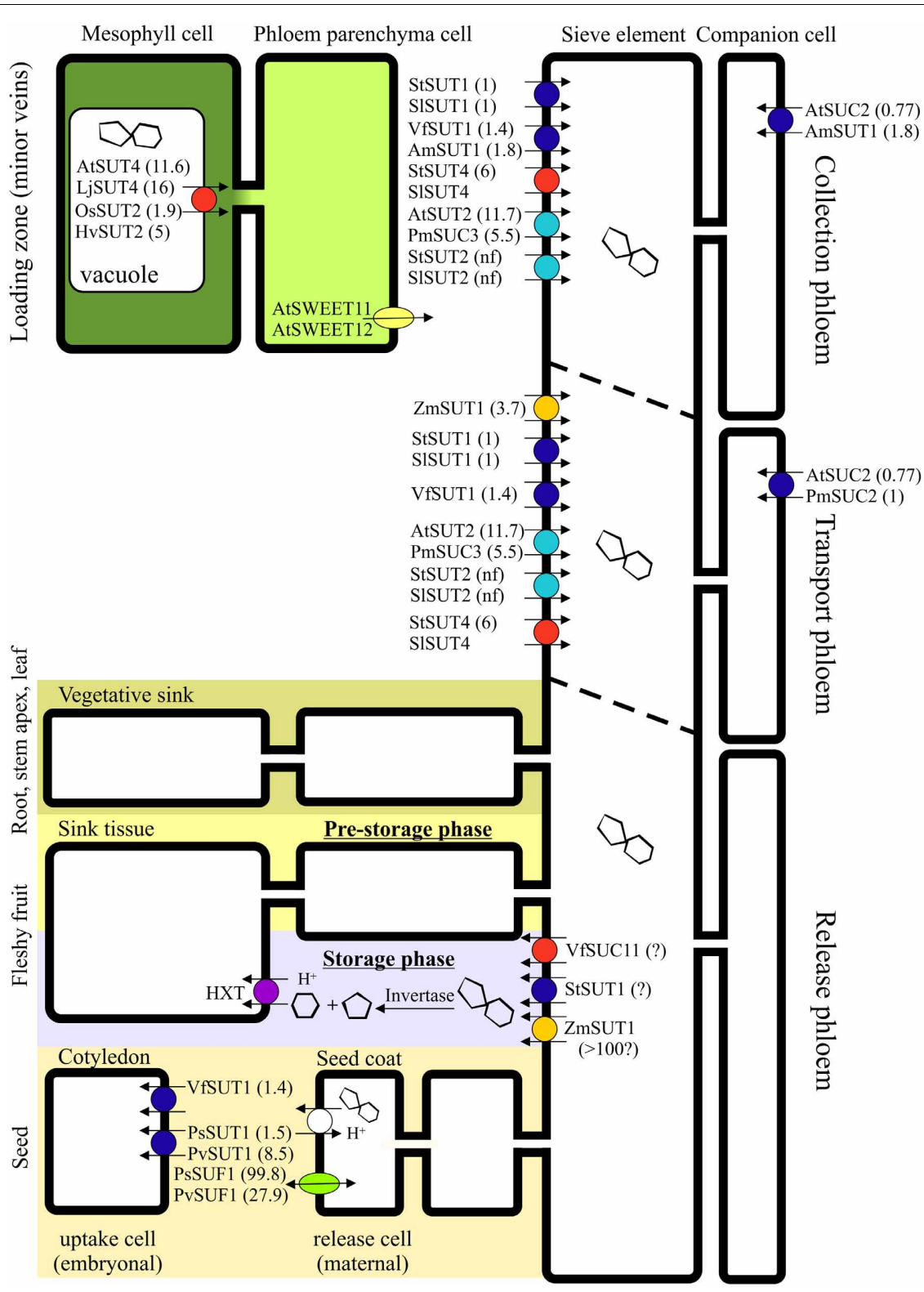

FIGURE 3 | Schematic presentation of the affinity constants of sucrose transporters involved in apoplasmic phloem loading, transport, and unloading. $K_{m}$ values were taken from (Riesmeier et al., 1993; Weber et al. 1997; Barker et al., 2000; Schulze et al., 2000; Weise et al., 2000; Weschke et al., 2000; Manning et al., 2001; Reinders et al., 2002; Barth et al., 2003; Knop et al., 2004; Carpaneto et al., 2005; Zhou et al., 2007; Eom et al., 2011; Gould et al., 2012). Sucrose transporters are indispensible for apoplasmic phloem loading, but play a rather marginal part in symplasmic phloem loading as it occurs in numerous species. In transport phloem, sucrose transporters are prominent under the usually prevailing source-limiting conditions, whereas their role is reduced under sink-limiting conditions. While phloem unloading in terminal leaf and root sinks occurs entirely symplasmically, the unloading path in larger sinks may include an apoplasmic step. Due to the obligatory symplasmic isolation of the embryo from the maternal seed-coat tissue in Pisum sativum and Phaseolus vulgaris, an apoplasmic loading step is required involving sucrose transporters and facilitators (Patrick, 2013). A sucrose/proton antiport mechanism of unknown identity was postulated in seed coats of Vicia faba (Fieuw and Patrick, 1993) and Phaseolus vulgaris (Walker et al., 1995). PsSUT1 was also localized in the vascular tissue of the seed coat, where it is assumed to play a role in sucrose efflux (Zhou et al., 2007). In fleshy fruits, phloem unloading often follows diverse routes in dependence of the developmental stage. After symplasmic unloading during the pre-storage phase, phloem unloading is assumed to occur apoplasmically during the storage phase (Ruan and Patrick, 1995; Zhang et al., 2006; Nie et al., 2010; Tegeder et al., 2013), while apoplasmic sieve-element unloading precedes symplasmic transport in the post-sieve-element pathway during the entire development of apples (Zhang et al., 2004). In walnuts, the pathway of unloading depends on the target tissue: photoassimilates are transported symplasmically to the seed coat, but apoplasmically to the fleshy pericarp (Wu et al., 2004). In potato tubers, apoplasmic unloading switches to symplasmic unloading during development (Viola et al., 2001). During the first phase of stolon development, the sucrose transporter StSUT1 is assumed to be involved in sucrose unloading form the phloem acting as a sucrose efflux transporter (Kühn et al., 2003). Sucrose transporters of the SUT1 clade are colored in blue, of the SUT2 clade in cyan, of the SUT3 clade in orange, whereas transporters of the SUT4 clade are colored in red laccording to the phylogenetic classification by Kühn and Grof, 2010). $K_{m}$ values (mM) of the transporters are displayed in brackets. 
towards adjacent cells are closed after microelectrode insertion.

(b) Two active systems are involved in sucrose uptake. Several studies postulated a second linear component in addition to active uptake resulting in biphasic kinetics (e.g., van Bel and Koops, 1985; Daie, 1987). This linear uptake was assigned to facilitated diffusion, but could be equally well the linear section of a low-affinity MM system. The latter opinion was corroborated by PCMS inhibition and FC stimulation of this linear component of sucrose uptake (A. J. E. van Bel and M. Tjaden, unpublished results). Active uptake by a low-affinity system would be in line with the continuously increasing depolarizations at higher sucrose concentrations (Figures 1E,H).

\section{CONSEQUENCES FOR CARBOHYDRATE PROCESSING IN INTACT PLANTS}

The uptake mode(s) has(have) a strong impact on sucrose processing along the phloem pathway. The existence of one sucrose uptake system in SEs of transport phloem would disclose a shift in the $K_{m}$ values of SEs from $1.8 \mathrm{mM}$ to approx. 6 to $7 \mathrm{mM}$ downwards along the plant axis (Table 1, NLSF, EH for MM). In parallel with the increase in the affinity constant, membrane potentials in SEs decline along the plant axis (Figure 1A), leading to reduced pmf-driven sucrose uptake (e.g., Hafke et al., 2005). A comparable voltage-dependence of $K_{m}$ values was already characterized for the sucrose carrier ZmSUT1 expressed in oocytes (Carpaneto et al., 2005). Carpaneto et al. (2005) showed, that that $K_{m}$ values for ZmSUT1 increased at more positive membrane voltages. For PPCs showing much higher $K_{m}$ values for sucrose uptake (>10 mM; Table 1), more detailed data analysis on kinetic properties of sucrose uptake is necessary. Recently, two efflux carriers mediating a key step in phloem loading have been characterized in Arabidopsis: AtSWEET11 and AtSWEET12. These two sucrose transporters are highly expressed in leaves and are both localized in the plasma membrane of phloem parenchyma cells (Chen et al., 2012). The atsweet11/atsweet12 double insertional mutant plants are defective in phloem loading and display a phenotype similar to AtSUC2 knock-out mutants with regard to sugar and starch accumulation (Gottwald et al., 2000). Both AtSWEET11 and AtSWEET12 seem to be different from the other proteins belonging to the SWEET family because of their low affinity to sucrose, with the $K_{m}$ values for an influx $\approx 70$ and efflux $>10 \mathrm{mM}$ (AtSWEET12). Because of the pH-independent transport, it was suggested that the sucrose translocation may rely on a uniport system (Chen et al., 2012).

It should be noted, that, pmf-driven uptake rates may be constant, since membrane potentials of PPCs did not change along the plant axis (Figure 1B). Both membrane potential gradients and $K_{m}$ gradients infer that the competitiveness of sieve elements declines downwards along the axis.

Carbohydrate partitioning and management strongly depend on the release/retrieval of photoassimilates along the phloem path under source-limiting conditions (Patrick and Offler, 1996; van Bel, 2003a,b; Hafke et al., 2005). The rate of (temporary) diversion of photoassimilates to axial sinks is determined by a competition between SE/CCs and PPCs (Hafke et al., 2005).
According to the present data, the relative competitiveness of PPCs tends to increase near the stem basis (ratio, Figure 1B). According to the $K_{m}$-values assuming one sucrose uptake system along the axis (Tables 1, 2), the competitiveness of SE/CCs is higher at low apoplasmic sucrose concentrations than at high concentrations which can be handled more easily by PPCs (having low-affinity uptake system). Under sink-limiting conditions, the amounts of photoassimilates available for the axial sinks are extremely high. Then, membrane uptake systems will be of minor importance since most of the photoassimilates move through open plasmodesmata towards the PPCs (Patrick and Offler, 1996). Under these circumstances, the low-affinity systems of PPCs may be quite useful for retrieval of massive amounts of sucrose leaking from the axial sink cells.

\section{PATCH-CLAMP RECORDINGS OF SUCROSE-INDUCED PROTON FLUXES IN SIEVE-ELEMENT PROTOPLASTS}

In previous studies, ZmSUT1 was heterologously expressed in oocytes and characterized functionally in detail using a patch-clamp approach (Carpaneto et al., 2005, 2010). The sucrose-coupled proton currents were reversible depending on the direction of the sucrose and $\mathrm{pH}$ gradients and the apparent affinity constant $K_{m}$ of ZmSUT1 exhibited a pronounced voltage and $\mathrm{pH}$-dependence (Carpaneto et al., 2005). The turnover rate of ZmSUT1 at a physiological membrane voltage of $-120 \mathrm{mV}$ is about $500 \mathrm{~s}^{-1}$ (Carpaneto et al., 2010). Based on this value, a transporter density of $10^{4} / \mu \mathrm{m}^{2}$ was calculated for oocytes expressing ZmSUT1 (Carpaneto et al., 2010), which exceeds by far the transporter densities to be expected in plasma membranes under natural conditions.

Using a similar patch-clamp approach (cf. Carpaneto et al., 2005), a sucrose $/ \mathrm{H}^{+}$symport activity was detected in the plasma membrane of SE protoplasts (Hafke et al., 2007) as indicated by an increase in inwardly directed currents (visible as downward deflections relative to the baseline) in response to sucrose supply. Neglecting possible rundown effects previously described for the $\mathrm{H}^{+}$/sucrose symporter ZmSUT1 (Carpaneto et al., 2005), negative currents with current densities $\mathrm{I} / \mathrm{C}_{\mathrm{m}}$ around $-0.2 \mathrm{pA} / \mathrm{pF}$ (Figure 2) were recorded in the presence of $100 \mathrm{mM}$ sucrose, a membrane voltage of $-106 \mathrm{mV}$ and a gradient of $2 \mathrm{pH}$ units. The observed current densities lie in the order of magnitude of sucrose-induced $\mathrm{H}^{+}$currents (Schulz et al., 2011; SUC4 transporters) or myo-inositol driven $\mathrm{H}^{+}$currents (Schneider et al., 2008) in vacuoles of Arabidopsis thaliana. To date, sucrose carrier activity in native membrane systems were measured solely in isolated vacuoles by the patch-clamp technique (Schulz et al., 2011). Given the detectable $\mathrm{H}^{+}$/sucrose symporter activity in the plasma membrane of SEs (Figure 2), SE protoplasts might become a suitable tool to characterize sucrose transporters in their natural membrane environment and hence complement the data set obtained with transporters expressed in heterologous systems like oocytes (Carpaneto et al., 2005, 2010).

\section{ACKNOWLEDGMENTS}

Tobias Kornemann and Andreas Bergman are acknowledged for excellent technical assistance. We thank Michael R. Thorpe for helpful discussions. 


\section{REFERENCES}

Akaike, H. (1973). "Information theory as an extension of the maximum likelihood principle," in Second International Symposium on Information Theory, eds B. N. Petrov and F. Csaki (Budapest: Akademiai Kiado), 267-281.

Ayre, B. (2011). Membrane-transport systems for sucrose in relation to whole-plant carbon partitioning. Mol. Plant 4, 377-394.

Barker, L., Kühn, C., Weise, A., Schulz, A., Gebhardt, C., Hirner, B., et al. (2000). SUT2, a putative sucrose sensor in sieve elements. Plant Cell 12, 1153-1164.

Barth, I., Meyer, S., and Sauer, N. (2003). PmSUC3: characterization of a SUT2/SUC3-type sucrose transporter from Plantago major. Plant Cell 15, 1375-1385.

Bertl, A., Blumwald, E., Coronado, R., Eisenberg, R., Findlay, G., Gradmann, D., et al. (1992). Electrical measurements on endomembranes. Science 258, 873-874.

Burnham, K. P., and Anderson, D. R. (2004). Multimodel inference: understanding AIC and BIC in model selection. Soc. Methods Res. $33,261-304$

Carpaneto, A., Geiger, D., Bamberg, E., Sauer, N., Fromm, J., and Hedrich, R. (2005). Phloem-localized, proton-coupled sucrose carrier ZmSUT1 mediates sucrose efflux under the control of the sucrose gradient and the proton motive force. J. Biol. Chem. 280, 21437-21443.

Carpaneto, A., Koepsell, H., Bamberg, E., Hedrich, R., and Geiger, D. (2010). Sucrose- and $\mathrm{H}^{+}$dependent charge movements associated with the gating of sucrose transporter ZmSUT1. PLoS ONE 5:e12605. doi: 10.1371/journal.pone.0012605

Chen, L. Q., Qu, X. Q., Hou, B. H., Sosso, D., Osorio, S., Fernie, A. R., et al. (2012). Sucrose efflux mediated by SWEET proteins as a key step for phloem transport. Science $335,207-211$.

Daie, J. (1987). Sucrose uptake in isolated phloem of celery is a single saturable transport system. Planta $171,474-482$.

Delrot, S., and Bonnemain, J.-L. (1981). Involvement of protons as a substrate for the sucrose carrier during phloem loading in Vicia faba leaves. Plant Physiol. 67, 560-564.

Eom, J. S., Cho, J. I., Reinders, A., Lee, S. W., Yoo, Y., Tuan, P. Q., et al. (2011). Impaired function of the tonoplastlocalized sucrose transporter in rice, OsSUT2, limits the transport of vacuolar reserve sucrose and affects plant growth. Plant Physiol. 157, 109-119.

Eschrich, W., Evert, R. F., and Young, J. H. (1972). Solution flow in tubular semipermable membranes. Planta 107, 279-300.

Fieuw, S., and Patrick, J. W. (1993). Mechanisms of photosynthate efflux from Vicia faba L. seed coats. J. Exp. Bot. 44, 65-74.

Gardner, M. L. G., and Atkinson, G. L. (1982). Kinetic analysis of transport processes in the intestine and other tissues. Clin. Sci. 63,405-414.

Geiger, D. (2011). Plant sucrose transporters from a biophysical view. Mol. Plant 4, 395-406.

Gillis, K. D. (1995). "Techniques for membrane capacitance measurements," in Single Channel Recordings, eds B. Sakmann and E. Neher (New York, NY: Plenum Press), 155-197.

Gottwald, J. R., Krysan, P. J., Young, J. C., Evert, R. F., and Sussman, M. R. (2000). Genetic evidence for the in planta role of phloem-specific plasma membrane sucrose transporters. PNAS 97, 13979-13984.

Gould, N., Thorpe, M. R., and Minchin, P. E. H. (2004). Direct measurements of sieve element hydrostatic pressure reveal strong regulation of sieve element hydrostatic pressure after pathway blockage. Funct. Plant Biol. 31, 987-993.

Gould, N., Thorpe, M. R., Pritchard, J., Christeller, J. T., Williams, L. E., Roeb, G., et al. (2012). AtSUC2 has a role for sucrose retrieval along the phloem pathway: evidence from carbon-11 tracer studies. Plant Sci. 188-189, 97-101.

Hafke, J. B., van Amerongen, J. K., Kelling, F., Furch, A. C. U., Gaupels, F., and van Bel, A. J. E. (2005). Thermodynamic battle for photosynthate acquisition between sieve tubes and adjoining parenchyma in transport phloem. Plant Physiol. $138,1527-1537$

Hafke, J. B., Furch, A. C. U., Reitz, M. U., and van Bel, A. J. E. (2007) Functional sieve element protoplasts. Plant Physiol. 145, 703-711.

Hofstee, B. H. J. (1959). Non-inverted versus inverted plots in enzyme kinetics. Nature 184, 1296-1298.

Kang, Y., Outlaw, W. H. Jr., Fiore, G. B., and Riddle, K. A. (2007). Guard cell apoplastic photosynthate accumulation corresponds to a phloemloading mechanism. J. Exp. Bot. 58, 4061-4070.

Kempers, R., Ammerlaan, A., and van Bel, A. J. E. (1998). Symplasmic constriction and ultrastructural features of the sieve element/companion cell complex in the transport phloem of apoplasmically and symplasmically phloem-loading species. Plant Physiol. 116, 271-278.

Knoblauch, M., and van Bel, A. J. E. (1998). Sieve tubes in action. Plant Cell 10, 35-50.

Knop, C., Stadler, R., Sauer, N., and Lohaus, G. (2004). AmSUT1, a sucrose transporter in collection and transport phloem of the putative symplastic phloem loader Alonsoa meridionalis. Plant Physiol. 134, 204-214.

Kühn, C. (2003). A comparison of the sucrose transporter systems of different plant species. Plant Biol. 5, 215-232.

Kühn, C., Hajirezaei, M. R., Fernie, A. R., Roessner-Tunali, U., Czechowski, T., Hirner, B., et al. (2003). The sucrose transporter StSUT1 localizes to sieve elements in potato tuber phloem and influences tuber physiology and development. Plant Physiol. 131, 102-113.

Kühn, C., and Grof, C. P. (2010). Sucrose transporters of higher plants. Curr. Opin. Plant Biol. 13, 288-298.

Lalonde, S., Tegeder, M., Throne-Holst, M., Frommer, W., and Patrick, J. W. (2003). Phloem loading and unloading of sugars and amino acids. Plant Cell Environ. 26, 37-56.

Lichtner, F. T., and Spanswick, R. M (1981). Electrogenic sucrose transport in developing soybean cotyledons. Plant Physiol. 67, 869-874.

Manning, K., Davies, C., Bowen, H. C. and White, P. J. (2001). Functional characterization of two ripeningrelated sucrose transporters from grape berries. Ann. Bot. 87, 125-129.

Minchin, P. E. H., and Thorpe, M. R (1984). Apoplastic phloem unloading in stem of bean. J. Exp. Bot. 35 , 538-550.

Minchin, P. E. H., and Thorpe, M. R. (1987). Measurement of unloading and reloading of photo-assimilate within the stem of bean. J. Exp. Bot. $38,211-220$.

Motulsky, H., and Christopoulos, A. (2003). Fitting models to Biological Data Using Linear and Nonlinear Regression. San Diego, CA: GraphPad Software, Inc., 143-148.

Neher, E. (1992). Correction for liquid junction potentials in patch-clamp experiments. Methods Enzymol. 207, 123-130.

Ng, B., and Barry, H. (1995). The measurement of ionic conductivities and mobilities of certain less common organic ions needed for junction potential corrections in elelctrophysiology. J. Neurosci. Methods 56, 37-41.

Nie, P., Wang, X., Hu, L., Zhang, H., Zhang, J., Zhang, Z., et al. (2010). The predominance of the apoplasmic phloem-unloading pathway is interrupted by a symplasmic pathway during chinese jujube fruit development. Plant Cell Physiol. 51, 1007-1018.

Oparka, K. J., Duckett, C. M., Prior, D. A. M., and Fisher, D. B. (1994). Realtime imaging of phloem unloading in the root tip of Arabidopsis. Plant J. 6, 759-766.

Patrick, J. W. (2013). "Fundamentals of phloem transport physiology," in Phloem: Molecular Cell Biology, Systemic Communication, Biotic Interactions, eds G. A. Thompson and A. J. E. van Bel (Hoboken, NJ: Wiley-Blackwell), 30-59.

Patrick, J. W., and Offler, C. E. (1996). Post-sieve element transport of photoassimilates in sink regions. J. Exp. Bot. 47, 1165-117.

Patrick, J. W., and Turvey, P. M. (1981). The pathway of radial transfer of photosynthate in decapitated stems of Phaseolus vulgaris L. Ann. Bot. 47 611-621.

Reinders, A., Schulze, W., Thaminy, S., Stagljar, I., Frommer, W. B., and Ward, J. M. (2002). Intraand intermolecular interactions in sucrose transporters at the plasma membrane detected by the splitubiquitin system and functional assays. Structure 10, 763-772. doi: 10.1016/S0969-2126(02)00773-6

Reinders, A., Sivitz, A. B., Starker, C. G., Gantt, J. S., and Ward, J. M. (2008). Functional analysis of LjSUT4, a vacuolar sucrose transporter from Lotus japonicus. Plant Mol. Biol. 68, 289-299. doi: 10.1007/s11103-0089370-0

Reinhold, L., and Kaplan, A. (1984). Membrane transport of sugars and amino acids. Annu. Rev. Plant Physiol. 35, 45-83. doi: 10.1146/ annurev.pp.35.060184.000401

Rhodes, J. D., Thain, J. F., and Wildon, D. C. (1996). The pathway for systemic electrical signal conduction in the wounded tomato plant. Planta 200, 50-57. doi: 10.1007/BF00196648

Riesmeier, J. W., Hirner, B., and Frommer, W. B. (1993). Potato sucrose transporter expression in minor veins indicates a role in phloem loading. Plant Cell 5, 1591-1598.

Ritchie, R. J., and Prvan, T. (1996). Current statistical methods for 
estimating the $K_{m}$ and $\mathrm{V}_{\text {max }}$ of Michaelis-Menten kinetics. Biochem. Edu. 24, 196-206. doi: 10.1016/S0307-4412(96)00089-1

Ruan, Y.-L., and Patrick, J. W. (1995). The cellular pathways of postphloem sugar transport in developing tomato fruit. Planta 196, 434-444. doi: 10.1007/BF00203641

Sauer, N. (2007). Molecular physiology of higher plant sucrose transporters. FEBS Lett. 581, 2309-2317. doi: 10.1016/j.febslet. 2007.03.048

Schneider, S., Beyhl, D., Hedrich, R., and Sauer, N. (2008). Functional and physiological characterization of Arabidopsis INOSITOL TRANSPORTER1, a novel tonoplast-localized transporter for myo-Inositol. Plant Cell 20, 1073-1087. doi: 10.1105/tpc.107. 055632

Schulz, A., Beyhl, D., Marten, I., Wormit, A., Neuhaus, E., Poschet, G., et al. (2011). Proton-driven sucrose symport and antiport are provided by the vacuolar transporters SUC4 and TMT1/2. Plant J. 68, 129-136. doi: 10.1111/j.1365313X.2011.04672.x

Schulze, W., Weise, A., Frommer, W. B., and Ward, J. M. (2000). Function of the cytosolic N-terminus of sucrose transporter AtSUT2 in substrate affinity. FEBS Lett. 485, 189-194. doi: 10.1016/S0014-5793 (00)02180-3

Tegeder, M., Ruan, Y.-L., and Patrick, J. W. (2013). "Roles of plasma membrane transporters in phloem function," in Phloem: Molecular Cell Biology, Systemic Communication, Biotic Interactions, eds G. A. Thompson and A. J. E van Bel (Hoboken, NJ: Wiley-Blackwell), 63-101.

Thomson, A. B. R. (1977). Limitations of the Eadie-Hofstee plot to estimate kinetic parameters of intestinal transport in the presence of an unstirred water layer. J. Membr. Biol. 47, 39-57.

Thomson, A. B. R., and Dietschy, J. M. (1977). Derivation of the equations that describe the effects of unstirred water layers on the kinetic parameters of active transport processes in the intestine. J. Theor. Biol. 64, 277-294. doi: 10.1016/00225193(77)90357-5

van Bel, A. J. E. (1996). Interaction between sieve element and companion cell and the consequences for photoassimilate distribution. Two structural hardware frames with associated software packages in dicotyledons? J. Exp. Bot. 47, 1129-1140. doi: 10.1093/jxb/47.Special_Issue.1129

van Bel, A. J. E. (2003a). The phloem, a miracle of ingenuity. Plant Cell Environ. 26, 125-150.

van Bel, A. J. E. (2003b). Transport phloem: low profile, high impact. Plant Physiol. 131, 1509-1510.

van Bel, A. J. E., and Koops, A. (1985). Uptake of ${ }^{14} \mathrm{C}$-sucrose in isolated minor vein networks of Commelina benghalensis L. Planta 164, 362-369. doi: 10.1007/BF00402947

van Bel, A. J. E., and van Rijen, H. V. M. (1994). Microelectroderecorded development of the symplasmic autonomy of the sieve element/companion cell complex in the stem phloem of Lupinus luteus L. Planta 192, 165-175. doi: 10.1007/BF01089031

van Bel, A. J. E., and Hafke, J. B. (2005). "Physiochemical determinants of phloem transport," in Vascular Transport in Plants, eds N. M. Holbrook and M. Zwieniecki (Amsterdam: Elsevier), 19-44. doi: 10.1016/B978-01208 8457-5/50004-6

van der Schoot, C., and van Bel, A. J. E. (1989). Glass microelectrode measurements of sieve tube membrane potentials in internode discs and petiole strips of tomato (Solanum lycopersicum L.). Protoplasma 149, 144-154. doi: 10.1007/BF01322986

Viola, R., Roberts, A. G., Haupt, S., Gazzani, S., Hancock, R. D., Marmiroli, N., et al. (2001). Tuberization in potato involves a switch from apoplastic to symplastic phloem unloading. Plant Cell 13, 385-398.

Voitsekhovskaja, O. V., Pakhomova, M. V., Syutkina, A. V., Gamalei, Y. V., and Heber, U. (2000). Compartmentation of assimilate fluxes in leaves. II. Apoplastic sugar levels in leaves of plants with different companion cell types. Plant Biol. 2, 107-112. doi: 10.1055/s-2000-9459

Walker, N. A., Patrick, J. W., Zhang, W.-H., and Fieuw, S. (1995). Efflux of photosynthate and acid from developing seed coats of Phaseolus vulgaris L.: a chemisosmotic analysis of pump-driven efflux. J. Exp. Bot. 46, 539-549.

Weber, H., Borisjuk, L., Heim, U., Sauer, N., and Wobus, U. (1997). A role for sugar transporters during seed development: molecular characterization of a hexose and a sucrose carrier in fava bean seeds. Plant Cell 9, 895-908. doi: 10.1105/tpc.9.6.895

Weise, A., Barker, L., Kühn, C., Lalonde, S., Buschmann, H., Frommer, W. B., et al. (2000). A new subfamily of sucrose transporters, SUT4, with low affinity/high capacitance localized in enucleate sieve elements of plants. Plant Cell 12, 1345-1355.

Weschke, W., Panitz, R., Sauer, N. Wang, Q., Neubohn, B., Weber, H., et al. (2000). Sucrose transport into barley seeds: molecular characterization of two transporters and implications for seed development and starch accumulation. Plant J. 21, 455-467. doi: 10.1046/j.1365313x.2000.00695.x

Winne, D. (1977). Correction of the apparent Michaelis constant, biased by an unstirred layer, if a passive transport component is present. Biochim. Biophys. Acta 464,118-126. doi: 10.1016/0005-2736(77)90375-3

Wright, J. P., and Fisher, D. B. (1981). Measurement of sievetube membrane potential. Plant Physiol. 65, 1133-1135. doi: 10.1104/pp.65.6.1133

Wu, G. L., Zhang, X. Y., Zhang, L. Y., Pan, Q. H., Shen, Y. Y., and Zhang, D. P. (2004). Phloem unloading in developing walnut fruit is symplasmic in the seed pericarp and apoplasmic in the fleshy pericarp. Plant Cell Physiol. 45, 1461-1470. doi: $10.1093 / \mathrm{pcp} / \mathrm{pch} 169$

Zhang, L. Y., Peng, Y. B., PelleschiTravier, S., Fan, Y., Lu, Y. F., Lu,
Y. M., et al. (2004). Evidence for apoplasmic phloem unloading in developing apple fruit. Plant Physiol. 135, 574-586. doi: 10.1104/pp.103.036632

Zhang, X. Y., Wang, X. L., Wang, X. F., Xia, G. H., Pan, Q. H., Fan, R. C., et al. (2006). A shift of phloem unloading from symplasmic to apoplasmic pathway is involved in developmental onset of ripening in grape berry. Plant Physiol. 142, 220-232. doi: 10.1104/pp.106.081430

Zhou, Y., Qu, H., Dibley, K. E., Offler, C. E., and Patrick, J. W. (2007) A suite of sucrose transporters expressed in coats of developing legume seeds includes novel $\mathrm{pH}$ independent facilitators. Plant J. 49, 750-764. doi: 10.1111/j.1365313X.2006.03000.x

Conflict of Interest Statement: The authors declare that the research was conducted in the absence of any commercial or financial relationships that could be construed as a potential conflict of interest.

Received: 19 March 2013; paper pending published: 05 May 2013; accepted: 04 July 2013; published online: 31 July 2013. Citation: Hafke JB, Höll S-R, Kühn C and van Bel AJE (2013) Electrophysiological approach to determine kinetic parameters of sucrose uptake by single sieve elements or phloem parenchyma cells in intact Vicia faba plants. Front. Plant Sci. 4:274. doi: 10.3389/fpls.2013.00274

This article was submitted to Frontiers in Plant Physiology, a specialty of Frontiers in Plant Science.

Copyright (C) 2013 Hafke, Höll, Kühn and van Bel. This is an open-access article distributed under the terms of the Creative Commons Attribution License (CC BY). The use, distribution or reproduction in other forums is permitted, provided the original author(s) or licensor are credited and that the original publication in this journal is cited, in accordance with accepted academic practice. No use, distribution or reproduction is permitted which does not comply with these terms. 